\title{
Установление подлинности сыров методом обращенно-фазовой ВЭЖХ
}

\author{
Ань Ван Нгуен ${ }^{1}$, Дейнека В.И. ${ }^{1}$, Хиен Чан Тхао Нгуен ${ }^{1}$, \\ Дейнека Л.А. ${ }^{1}$, Рудаков О.Б. ${ }^{2}$ \\ ${ }^{I}$ ФГАОУ ВПО «Белгородский государственный национальный исследовательский университет», \\ Белгород \\ ${ }^{2}$ ФБОУ ВО «Воронежский государственньий технический университет», Воронеж
}

Поступила в редакцию 4.09.2018 г.

DOI: https://doi.org/10.17308/sorpchrom.2018.18/609

В работе метод обращенно-фазовой ВЭЖХ использован для определения подлинности сыров. Для установления фальсификации сыров могут быть использованы, во-первых, метод отпечатков пальцев, по которому визуально, или прямым наложением хроматограмм эксперты оценивают идентичность хроматографических профилей. Более строгий количественный метод предполагает выбор характеристических пиков триацилглицеринов, площади которых используются для построения векторной модели. В таком случае выбор базиса зависит от предполагаемого типа фальсификации, а различие между образцами характеризуется углом между вектором для исследуемого образца и реперным вектором. При анализе 23 марок сыра было установлено, что большая часть из них изготовлена при использовании натурального коровьего молока. Но для 7 марок получены большие значения характеристических углов, а сопоставление полученных для этих марок хроматограмм позволило определить и характер фальсификации: за счет замены коровьего жира на пальмовое масло или заменители молочного жира на основе пальмового или подсолнечного масла. Показано, что для дифференциации сыров на основе коровьего и козьего молока также могут быть выбраны три характеристических пика.

Ключевые слова: подлинность сыров, метод отпечатков пальцев, векторная модель, триацилглицерины сыра, молочный жир, козий жир.

\section{The definition of authenticity of cheese trademarks by RP HPLC}

\author{
Anh Van Nguen ${ }^{1}$, Deineka V.I. ${ }^{1}$, Hien Tran Thao Nguen ${ }^{1}$, \\ Deineka L.A. ${ }^{1}$, Rudakov O.B. ${ }^{2}$

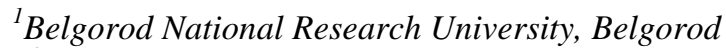 \\ ${ }^{2}$ Voronezh State Technical University, Voronezh
}

In this paper, the method of reversed-phase HPLC is used to determine the authenticity of real cheeses. To establish the falsification of cheeses two methods were proposed. The first method implies to compare chromatograms of the cheese under investigation with authentic sample of the fat known as the «fingerprint» method visually or by direct overlay of the chromatograms. A more rigorous quantitative method involves the selection of the three triacylglycerol (TAG) characteristic peaks the areas of which are used to build a vector model. In this case, the choice of basis depends on the intended type of falsification, and the difference between the samples is characterized by the angle between the vector for the sample and the reference vector. In the analysis of 23 brands of cheese, it was found that most of them are made using natural cow's milk. However, for 7 of the studied cheese grades, large values of characteristic angles were obtained. Comparison of chromatograms obtained for these grades with known chromatographic profiles of seed oils it possible to determine the nature of falsification: by replacing cow fat with palm or linoleic-oleic type oil. In 
this case area of TAG peaks with equivalent carbon numbers (ECN) 35.6, 37.5 and 47.2 may be explored to build the vector model. The first of them is representative for butyric acid containing TAG: the second - for trilinoleate concentration if some seed oils are used, and the third area is sensitive to palm butter edition. Three another TAG sensitive to exchange of cow milk by goat one were proposed to use in corresponding cases.

Keywords: cheese authenticity, fingerprint method, vector model, cheese triacylglycerines, cow milk fat, goat milk fat.

\section{Введение}

Сыр является важным продуктом переработки молока некоторых животных (коровьего, козьего, овечьего и др.). Но молочный жир относится к недешевому сырью, поэтому производители активно используют современные технологии пищевой промышленности, вытесняя (частично или полностью) молочный жир растительными маслами. По требованиям ГОСТ Р 52686-2006 «Сыры. Общие технические условия (с Поправками)» при производстве сыров в качестве основного сырья допустимо использование только молока и некоторых продуктов его переработки. Поэтому при наличии растительных жиров в составе сыра следует указывать, что это не настоящий сыр, а сырный продукт, хотя в принципе сырный продукт не является вредным или опасным для употребления, но при условии, что в нем использованы жиры, не подвергавшиеся высокотемпературному воздействию, которое имеет место при частичной гидрогенизации и дезодорации. Чаще всего полученные в результате переработки из растительных масел заменители молочного жира, увы, содержат вредные для здоровья транс-изомерные жирные кислоты, глицидиловые эфиры и эфиры 3хлорпропандиола $[1,2]$.

Об отставании методов анализа содержания и состава жиров и масел по действующим в России нормативам (ГОСТ, ТУ и др.) от современного уровня аналитических технологий уже отмечалось ранее $[3,4]$. Контроль содержания жира в молочной продукции, в том числе в сырах, выполняют в соответствие с ГОСТ 5867-90 «Молоко и молочные продукты. Методы определения жира или других продуктов переработки молока», или ГОСТ 32915-2014 «Молоко и молочная продукция. Определение жирнокислотного состава жировой фазы методом газовой хроматографии» требует доработки и дифференцированного подхода к конкретным видам продукции. Если для определения жира в молоке кислотный гидролиз необходим для разрушения эмульсии, то зачем этот же метод необходим для анализа доли жира в жировой продукции? Кроме того, оценка объема экстракта изоамиловым спиртом, или гексаном, используемая в методиках, довольно примитивна, поскольку в этих экстрагентах могут растворяться не только образовавшиеся при гидролизе высшие жирные кислоты, но и другие липоидные вещества. Не исключено, что в зависимости от матрицы продукта для исчерпывающей экстракции жиров требуется применение бинарных экстрагентов, отличающихся синергизмом в экстракционной способности.

Анализ метиловых эфиров жирных кислот (после переэтерификации пробы), входящих в состав триацилглицеринов (ТАГ) молочного жира, достаточно сложен из-за многокомпонентности - по литературным данным в масле насчитывают почти 400 (!) радикалов различных кислот $[5,6]$. При этом число возможных видов ТАГ, содержащих кислоты с долей выше 1 моль\% находится на уровне более 1300 . Но, с другой стороны, в связи с наличием фенотипических закономерностей распределение остатков жирных кислот по видам ТАГ далеко от статистического, поэтому реально на хроматограмме молочного жира обнаруживается порядка 50 пиков [6]. Обзор по возможностям аналитических методов в определении видового состава ТАГ молочного жира представлен в [7], при этом для эффективного контроля используют 
либо градиентные режимы, либо серию последовательно соединенных колонок с высокочувствительным (и дорогостоящим) детектированием по светорассеиванию.

Цель настоящей работы - разработка метода оценки качества сыров с использованием обращенно-фазовой ВЭЖХ с рефрактометрическим детектированием.

\section{Эксперимент}

Компонентный состав ТАГ жира сыров анализировали методом обращеннофазовой ВЭЖХ с использованием хроматографа Agilent 1260 Infinity с рефрактометрическим детектором R-401. Хроматографическая колонка 250×4.6 мм Kromasil 1005C18; подвижная фаза $100 \%$ ацетон $\left(0.8 \mathrm{~cm}^{3} / \mathrm{Mин}\right)$. Для записи и обработки хроматограмм использовали ПО «Мультихром 1.5». Для графического разделения смежных пиков использовали программу Magicplot student 2.7.2, с аппроксимацией пиков не модифицированными гауссианами. В качестве стандартного образца использовали масло сладко-сливочное, сорт высший (82.5\% жира), прошедшее экспертизу качества по ГОСТ 32261-2013 «Масло сливочное. Технические условия». Материал для исследования (сыры различных марок и изготовителей) был приобретен в магазинах г. Белгорода. В связи с применением не стандартизированных методик и с отсутствием государственной аккредитации лаборатории на выполнение химического анализа пищевой продукции, марки сыров и производители исследованных в работе сыров в тексте не указаны.

Для экстракции жира навеску измельченного сыра (0.5 г) переносили в стакан, добавляли натрий сернокислый безводный $\left(0.1\right.$ г), добавляли $20 \mathrm{~cm}^{3}$ петролейного эфира, сыр разминали стеклянной палочкой под слоем экстрагента и смесь выдерживали в ультразвуковой бане в течение 20 мин. Экстракт отделяли от твердого осадка фильтрованием через бумажный фильтр. Для экстракции использовали 2 последовательные порции экстрагента. Экстракты объединяли и петролейный эфир удаляли на вакуумном ротационном испарителе. По массе полученного остатка рассчитывали содержание жировой фазы в сыре. Для анализа липидов методом ВЭЖХ пробу полученного жира растворяли в подвижной фазе (в ацетоне).

\section{Обсуждение результатов}

Типичная хроматограмма стандартного образца молочного жира представлена на рис.1, А. Для записи хроматограммы требуется немногим более 10 мин, но метод не позволяет разделить все пики на хроматограмме.

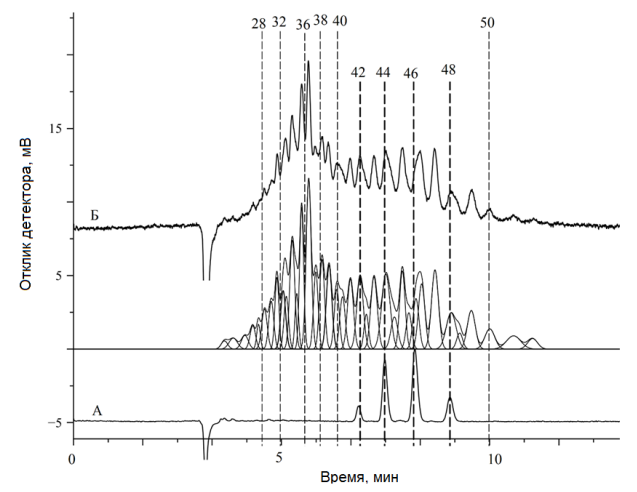

Рис 1. Разделение триацилглицеринов молочного жира по эквивалентому углеродному числу А - стандартные ТАГ (тримиристинат $\mathrm{ECN}=42$, димиристинатпальмитат $\mathrm{ECN}=44$, миристинат-дипальмитат $\mathrm{ECN}=46$ и трипальмитат $\mathrm{ECN}=48$ ), Б - молочный жир 
Экспериментально было установлено, что добавки ацетонитрила в подвижную фазу позволяют увеличить диапазон времен удерживания, но заметного улучшения разделения при этом добиться также не удается; при этом снижается растворимость масла и, соответственно, уменьшается чувствительность детектирования ТАГ. Проблема выделения индивидуальных компонентов или более узких фракций в суперпозиции пиков решается за счет обработки хроматограммы программой Magicplot student 2.7.2 (рис.1, A+).

На рис.1 представлена также хроматограмма синтетических ТАГ (рис.1, Б), полученных этерификацией глицерина смесью миристиновой и пальмитиновой кислот [8], которая может быть использована для классификации ТАГ по эквивалентным углеродным числам [9].

На рис. 2 представлены хроматограммы жиров пяти из 21 исследованных в настоящей работе марок сыров, на которых представлены и два образца с заменой молочного жира на растительные масла. Из указанных образцов два (№1 и №2) являются настоящими жирами с хроматограммой триацилглицеринов, визуально не отличимой от стандартного образца сливочного масла. Но сыры №3 и №4 по очевидному изменению хроматографического профиля отчетливо отличаются от первых двух. Более того, на основе опыта исследования растительных масел можно предположить, что один (образец №4) из исследованных образцов изготовлен с использованием в основном пальмового масла, а в образце №3 использована смесь пальмового масла с жиром на основе подсолнечного или кукурузного масла. Следовательно, для установления грубой фальсификации достаточно использовать метод «отпечатков пальцев» с визуальным контролем хроматографического профиля. Отметим, что визуально обнаруживаются различия в хроматографических профилях эталонного молочного жира и жира образца сыра №5 на том же рисунке. Основное отличие в данном случае состоит в том, что средний участок хроматограммы (с ТАГ с ЭУЧ в диапазоне $36 \div 44)$ в образце №5 содержит пики с большей интенсивностью по сравнению с молочным жиром. Но такое изменение следует предполагать в случае использования для приготовления сыра овечьего или козьего молока, содержащих большую долю ТАГ, образованных с участием радикалов кислот со средней длиной углеродной цепи (каприловой, С8, и каприновой, С10).

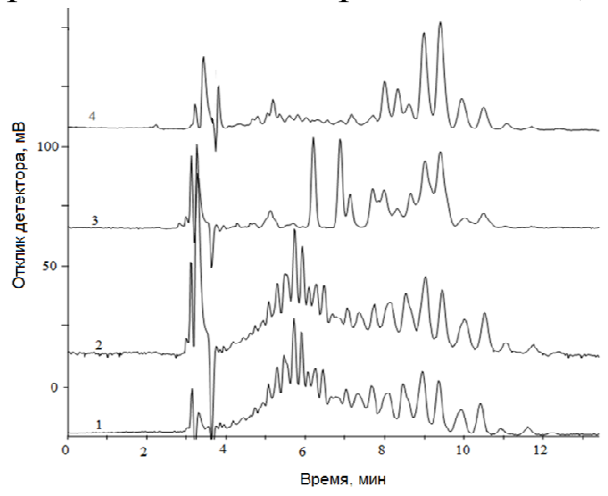

Рис. 2. Хроматограммы ацетоновых экстрактов некоторых сыров 1 - Сыр №12 (из табл.1), 2 - Сыр №5, 3 - Сыр №17, 4 - Сыр №20

В работе [10] была предложена векторная модель для количественной оценки подлинности масла какао в составе шоколада. Аналогичная модель предложена и в настоящей работе для контроля качества сыра. Строго говоря, для оценки качества сыра можно было бы использовать многомерный вектор, но привычнее и проще оценивать углы в трехмерном пространстве. При этом выбор векторов будет зависеть от возможного (предположительно основного) характера фальсификации. 
Импорт сравнительно дешевого пальмового масла в Россию в 2017 г. по статистическим данным составил 58 тыс. т., он несколько уменьшился из-за хорошего роста производства подсолнечного масла в прошлом году, поэтому использование пальмового масла или традиционных для нашей страны растительных масел (типа подсолнечного) могут считаться наиболее вероятными вариантами фальсификации. На рис.3 представлен один из вариантов таких координат. По предлагаемому подходу общее содержание масла в сыре определяется гравиметрическим методом, как указано в экспериментальной части. После записи хроматограммы определяют площади только трех указанных ниже пиков, рассчитывая долю каждого из них в сумме. Найденные доли используют в качестве координат векторной модели:

- координата по оси 0Х соответствует доле ТАГ с ЭУЧ, равным 35.6; ее величина определяется только содержанием молочного жира. Такого компонента нет ни в пальмовом масле, ни в линолево-олеиновом (предположительно подсолнечном) масле.

- координата по оси 0Y соответствует доле трилинолеата или иных ТАГ с ЭУЧ, равным или близким к 37.5, такой пик имеется и в молочном жире и в линолево-олеиновом масле, но практически отсутствует в пальмовом масле;

- координата по оси 0Z соответствует доле олеата-дипальмитата (ТАГ с ЭУЧ, равным 47.2); этот пик присутствует и в молочном жире и в пальмовом масле.

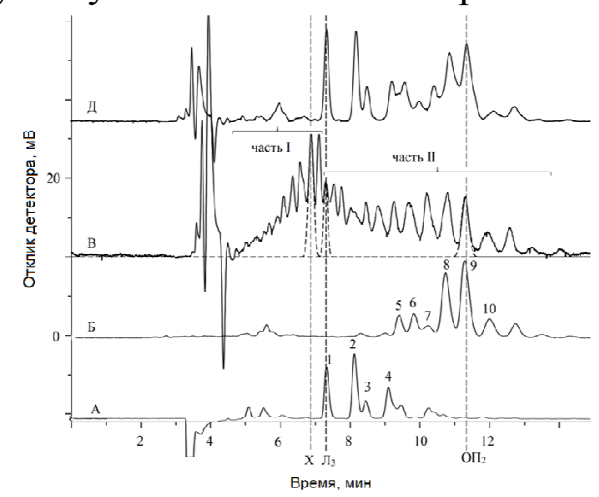

Рис. 3. Хроматографический профиль подсолнечного (А) и пальмового (Б) масел, жира молока «Белый город» (В) и сыра №17(Д). Триацилглицерины:

1 - $Л_{3}, 2$ - $Л_{2} \mathrm{O}, 3-Л_{2} \Pi, 4-Л_{2}, 5$ - ЛОП, 6 - ЛП $, 7-\mathrm{O}_{3}, 8-\mathrm{O}_{2} \Pi, 9-\mathrm{O}_{2}, 10-\mathrm{O}_{2} \mathrm{C}$

В таком случае возможно построение вектора сравнения $\left(\mathrm{R}_{0}\right)$, рис.3, полученного по данным для заведомо молочного жира (реперный вектор). Затем строится другой вектор для исследуемого (i-ого, $\mathrm{R}_{\mathrm{i}}$ ) сыра и определяют характеристический угол между двумя векторами, $\phi_{01}$.

$$
\phi_{01}=\arccos \frac{x_{1} x_{0}+y_{1} y_{0}+z_{1} z_{0}}{\sqrt{\left(x_{0}^{2}+y_{0}^{2}+z_{0}^{2}\right)\left(x_{1}^{2}+y_{1}^{2}+z_{1}^{2}\right)}}
$$

Результаты применения векторной модели к анализу масел 21 сорта сыра представлены в табл.1.

Таблица 1. Результаты применения векторной модели к 21 сортам сыров

\begin{tabular}{|c|c|c|c|c|c|}
\hline \multirow{2}{*}{ Объекты } & $\begin{array}{c}\text { Масличность, } \\
\text { масс \% (n=3; } \\
\pm 0.1 \%)\end{array}$ & \multicolumn{2}{|c|}{ Координаты, мол. доли } & Величина угла $\phi_{01}$, град \\
\cline { 3 - 6 } & 2 & 3 & 4 & 5 & 6 \\
\hline Молочный жир & 100 & 0.446 & 0.228 & 0.326 & 0.00 \\
\hline \multicolumn{7}{|c|}{ Сорта сыров } \\
\hline
\end{tabular}




\begin{tabular}{|c|c|c|c|c|c|}
\hline 1 & 2 & 3 & 4 & 5 & 6 \\
\hline №1 & 26.0 & 0.442 & 0.22 & 0.338 & 1.46 \\
\hline №2 & 24.1 & 0.449 & 0.227 & 0.324 & 0.35 \\
\hline №3 & 26.0 & 0.467 & 0.216 & 0.317 & 2.39 \\
\hline №4 & 25.9 & 0.450 & 0.212 & 0.338 & 1.98 \\
\hline №5 & 28.0 & 0.457 & 0.234 & 0.309 & 1.95 \\
\hline №6 & 26.4 & 0.447 & 0.222 & 0.332 & 0.84 \\
\hline №7 & 27.1 & 0.452 & 0.229 & 0.319 & 0.83 \\
\hline №8 & 27.2 & 0.458 & 0.212 & 0.330 & 1.96 \\
\hline №9 & 28.3 & 0.445 & 0.217 & 0.338 & 1.55 \\
\hline №10 & 26.5 & 0.465 & 0.213 & 0.322 & 2.32 \\
\hline №11 & 27.1 & 0.438 & 0.241 & 0.321 & 1.43 \\
\hline №12 & 32.8 & 0.430 & 0.225 & 0.345 & 2.36 \\
\hline №13 & 27.8 & 0.434 & 0.233 & 0.334 & 1.42 \\
\hline №14 & 37.3 & 0.460 & 0.300 & 0.241 & 10.7 \\
\hline №15 & 33.2 & 0.434 & 0.260 & 0.306 & 3.7 \\
\hline №16 & 28.1 & 0.107 & 0.194 & 0.699 & 43.1 \\
\hline №17 & 29.5 & 0.020 & 0.389 & 0.591 & 46.7 \\
\hline №18 & 24.2 & 0.037 & 0.030 & 0.933 & 54.1 \\
\hline №19 & 32.4 & 0.067 & 0.103 & 0.829 & 49.8 \\
\hline №20 & 24.3 & 0.096 & 0.136 & 0.769 & 46.4 \\
\hline №21 & 27.4 & 0.023 & 0.181 & 0.796 & 50.5 \\
\hline №22 ко3นй* & 28.3 & 0.436 & 0.224 & 0.34 & 1.67 \\
\hline №23 ове4uй* & 30.9 & 0.447 & 0.231 & 0.322 & 0.50 \\
\hline * & & & & \\
\hline
\end{tabular}

* - по данным сертификатов.

По представленным данным искомый угол для первых 13 сортов сыра таблицы 1 не превышает 2.5 градуса, что можно считать свидетельством изготовления сыра из коровьего молока. Относительно большой угол для образца №14 (с учетом хроматографического профиля) может быть связан с тем, что при его приготовлении использовали масло типа козьего или овечьего. Образцы №16-21 были изготовлены из растительного масла, поэтому должны называться сырным продуктом.

Образцы №22 и №23 по отклонению вектора от реперного вектора неотличимы от коровьего жира, но, по словам продавцов, они были изготовлены из козьего и овечьего молока. Понятно, что для дифференциации между такими тремя жирами требуется выбор иных базисных векторов, который был произведен так, как указано на рис.4.

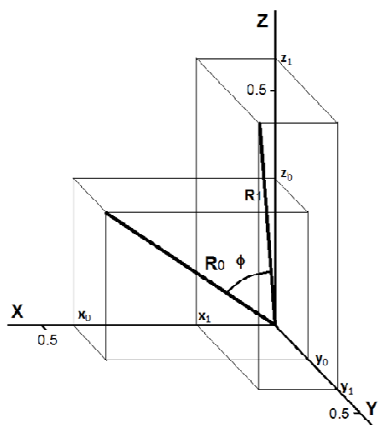

Рис. 4. Векторная модель для оценки фальсификации сыра пальмовым и подсолнечным маслами: $\mathrm{R}_{0}$ - реперный вектор; $\mathrm{R}_{1}$ - вектор для сыра №17.

В качестве одной из чувствительных к типу жира координат выбрана доля триацилглицеринов со средними значениями ЭУЧ. Результат сопоставления масел сыров по указанным на рис.5 координатам представлен в табл.2. 


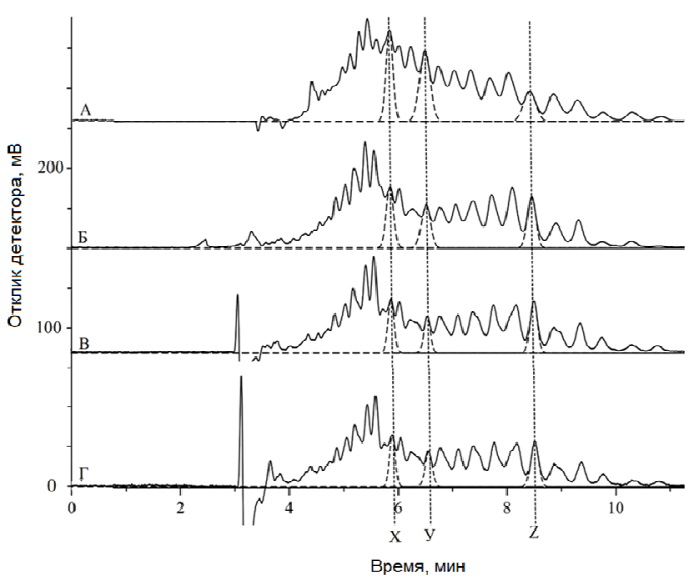

Рис. 5. Выбор векторов для дифференциации коровьего, козьего и овечьего жира. Хроматограмма жира козьего молока (А), коровьего молока (Б), сыра из фальсификатов козьего (В) и овечьего (Г) жиров

Таблица 2. Результаты применения векторной модели для дифференциации сыров из коровьего и козьего молока

\begin{tabular}{|c|c|c|c|c|}
\hline \multirow{2}{*}{ Объекты } & \multicolumn{3}{|c|}{ Координаты, мол. доли } & \multirow{2}{*}{ Величина угла $\phi_{01}$, град } \\
\cline { 2 - 5 } & $\mathrm{x}_{i}$ & $\mathrm{y}_{i}$ & $\mathrm{z}_{i}$ & \\
\hline Жир коровьего молока & 0.355 & 0.244 & 0.401 & 0.0 \\
\hline Жир козьего молока & 0.400 & 0.381 & 0.220 & 22.5 \\
\hline Сыр №14 & 0.434 & 0.342 & 0.224 & 21.1 \\
\hline Сыр №14* & \multicolumn{3}{|l}{} & 4.9 \\
\hline Сыр №22 (козий?) & 0.350 & 0.253 & 0.398 & 1.0 \\
\hline Сыр №23 (овечий?) & 0.327 & 0.281 & 0.392 & 4.6 \\
\hline
\end{tabular}

Сравнение жира козьего и коровьего молока по векторной модели в данном случае указывает на значительное различие между ними (угол между векторами составляет 22.5 градуса), что подтверждает высокую эффективность выбранных в данном случае координат к предполагаемой фальсификации. В таком случае сыр, изготовленный, по документации ретейлера или производителя, из козьего молока изготовлен на самом деле из коровьего молока, а вот сыр овечьего молока несколько отличается от сыра из коровьего молока, но степень отклонения установить невозможно, поскольку для контроля в эксперименте отсутствовал эталонный образец жира из овечьего молока. Но судя по литературным данным о составе ТАГ овечьего молока в сравнении с козьим [11], фальсификация весьма вероятна и в данном случае. С предложенным выбором координат можно вернуться к анализу образца сыра №14, табл.2. Характеристический угол этого образца по отношению к коровьему жиру близок к характеристическому углу козьего жира по отношению к тому же реперному вектору. Но если в качестве реперного вектора взять вектор для козьего жира, то характеристический угол для образца сыра №14 уменьшается до примерно 5 градусов. Это не противоречит гипотезе о происхождении жира из молока типа овечьего или козьего.

\section{Заключение}

Использование обращенно-фазовой ВЭЖХ при контроле состава триацилглицеринов сыров позволяет устанавливать подлинность продукции на качественном уровне по методу отпечатков пальцев, и на количественном уровне по предложенной 
векторной модели, выбор басиса в которой определяется характером возможной фальсификации.

\section{Список литературы}

1. Журавлев А.В. Трансжиры: что это такое и с чем их едят (полный вариант). М.:2012. $138 \mathrm{c}$.

2. Степанова Л.И., Потепкин М.С. // Молочная промышленность. 2018. № 5. С. 20-21

3. Дейнека В.И., Дейнека Л.А., Анисимович И.П., Туртыгин А.В. // Методы оценки соответствия. 2007. № 6. С. 10-11.

4. Рудаков О.Б., Полянский К.К., Рудакова Л.В. // Переработка молока. 2018. № 2 (221). C. 54-56.

5. Nájera A.I., Barcina Y., de Renobales M., Barron L.J.R. // Chromatographia. 1998. Vol.47. No 9-10. pp. 579-586.

6. Robinson N.P., MacGibbon A.K.H. // J. Amer. Oil Chem. Soc. 1998. Vol. 75. pp. 993999.

\section{References}

1. Zhuravlev A.V. Transzhiry: chto eto takoye i s chem ikh yedyat (polnyy variant), M., 2012, $138 \mathrm{p}$.

2. Stepanova L.I., Potemkin M.S., Molochnaya promyshlennost', 2018, № 5, pp. 20-21.

3. Deineka V.I., Deineka L.A., Anisimovitch I.P., Turtygin A.V., Metody ocenki sootvetstviya, 2007, No 6, pp. 10-11.

4. Rudakov O.B., Polyanskiy K.K., Rudakova L.V., Pererabotka moloka, 2018, No 2 (221), pp. 54-56.

5. Nájera A.I., Barcina Y., de Renobales M., Barron L.J.R., Chromatographia, 1998, Vol. 47, pp. 579-586. https://doi.org/10.1007/BF02467499.

6. Robinson N.P., MacGibbon A.K.H., J. Amer. Oil Chem. Soc., 1998, Vol. 75, pp. 993999. https://doi.org/10.1007/s11746-998-02773.

Ань Ван Нгуен - аспирант кафедры общей химии, Белгородский государственный национальный исследовательский университет, Белгород

Дейнека Виктор Иванович - профессор кафедры общей химии, д.х.н., Белгородский государственный национальный исследовательский университет, Белгород
7. Gastaldi D., Medana C., Giancotti V., Aigotti R. et al. // Eur. J. Lipid Sci. Technol. 2011. Vol. 113. pp. 197-207.

8. Дейнека В.И., Дейнека Л.А., Анисимович И.П., Перистый В.А. и др. // Заводская лаборатория. 2008. Т. 74. № 3. С. 15-19.

9. Podlaha O., Töregård B. // J. Sep. Sci. 1982. Vol. 5. pp. 553-558.

10. Индина И.В., Туртыгин А.В., Дейнека В.И., Дейнека Л.А. // Сорбиионные и хроматографические прочессы. 2013. Т. 13. № 1. C. 23-32.

11. Barron L.J.R., M. Hierro T.G., SantaMaria G. // J. Dairy Res. 1990. Vol. 57. pp. 517-526.

7. Gastaldi D., Medana C., Giancotti V., Aigotti R. et al., Eur. J. Lipid Sci. Technol., 2011, Vol. 113, pp. 197-207. https://doi.org/10.1002/ejlt.201000068.

8. Deineka V.I., Deineka L.A., Anisimovitch I.P., Peristyj V.A. et al., Zavodskaya laboratoriya, 2008, Vol. 74, No 3, pp. 15-19.

9. Podlaha O., Töregård B., J. Sep. Sci., 1982, Vol. 5, pp. 553-558. https://doi.org/10.1002/jhrc.1240051007.

10. Indina I.V., Tyrtygin A.V., Deineka V.I., Deineka L.A., Sorbtsionnye $i$ khromatograficheskie protsessy, 2013, Vol. 13, No 1, pp. 2332.

11. Barron L.J.R., M. Hierro T.G., SantaMaria G., J. Dairy Res., 1990, Vol. 57, pp. 517526.

Anh Van Nguyen - postgraduate of Common Chemistry Chair of Institute of Engineering Technologies and Natural Sciences of Belgorod State National Research University. e-mail: vananhkhoahoasp2@gmail.com

Deineka Victor I. - professor of Common Chemistry Chair of Institute of Engineering Technologies and Natural Sciences of Belgorod State National Research University. Dr. Sci. (Chemistry), e-mail: deineka@bsu.edu.ru 
Хиен Чан Тхао Нгуен - студент, Белгородский государственный национальный исследовательский университет, Белгород

Дейнека Людмила Александровна - доцент кафедры общей химии, к.х.н., Белгородский государственный национальный исследовательский университет

Рудаков Олег Борисович - д.х.н., заведующий кафедрой химии и химической технологии материалов, Воронежский государственный технический университет
Hien Tran Thao Nguyen - student of Belgorod State National Research University.

Deineka Ludmila A. - professor assistant of Common Chemistry Chair of Institute of Engineering Technologies and Natural Sciences of Belgorod State National Research University. Ph.D. (Chemistry), e-mail: deyneka@bsu.edu.ru

Rudakov Oleg B. - Dr. Sci (Chemistry), head of Department of chemistry and chemical technology of materials of Voronezh state technical University, Voronezh. E-mail: robi57@mail.ru 